\title{
Macau, visíveis e invisíveis do espaço, em Infraestruturas, de Alberto Estima de Oliveira
}

Monica Simas (USP) ${ }^{1}$

Resumo: O texto busca evidenciar os espaços visíveis e invisíveis da poética de Alberto Estima de Oliveira, poeta português que viveu em Macau por mais de 20 anos, cruzando elementos de uma geografia simbólica com a experiência urbana e cultural a partir da leitura e análise do livro Infraestruturas, re-publicado em edição bilingue com tradução para o chinês de Yao Jingming, no ano de 1999.

Palavras-chave: literatura de Macau; poesia e experiência urbana; interculturalidade.

"Pergunto-me ao chegar, se alguma vez cheguei/como seria a vida que se dizia calma/ neste minúsculo resto do corpo da cidade". (Alberto Estima de Oliveira, "Alto Contraste", Revista de Cultura, 1996)

\section{Provocação}

No início do século XX, em Portugal, o escritor e artista plástico José de Almada Negreiros lançava o seu Manifesto da Exposição de Amadeo de Souza-Cardoso (Imprensa Nacional-Casa da Moeda, 1992), convocando os portugueses a descobrirem-se para o seu tempo presente, a observarem a arte da sua contemporaneidade. A provocação assim se explicitava:

Amadeo de Souza-Cardoso é a primeira descoberta de Portugal na Europa no século XX. O limite da descoberta é infinito porque o sentido da Descoberta muda de substância e cresce em interesse - por isso que a Descoberta do Caminho Marítimo pra Índia é menos importante que a Exposição de Amadeo de Souza-Cardoso na Liga Naval de Lisboa (ALMADA NEGREIROS, 1992, p. 30).

Ela fez parte de um despertar de alguns artistas para o "ismos" que se desenvolviam nos países próximos e, especialmente, para o futurismo. A ação futurista durou um curtíssimo espaço de tempo, mas marcou profundamente

\footnotetext{
${ }^{1}$ Monica Simas é professora da Área de Literatura Portuguesa, coordenadora do LIA (Laboratório de Interlocuções com a Ásia) e do Grupo de Pesquisa "(Pt. Oriente) Portugal e o Oriente: literaturas, línguas e culturas". Atualmente, desenvolve as pesquisas: "Macau na escrita. Escritas de Macau" e "Portugal e o Contemporâneo: paisagens, vazios e afetos", no DLCV, FFLCH, USP. Email:monicasimas@usp.br
} 
todas as gerações posteriores. Amadeo de Souza-Cardoso, apesar de ele mesmo se considerar mais modernista do que futurista, iria manifestar em seu trabalho um verdadeiro conhecimento sobre aquela arte/atitude nova. Tanto a ação futurista quanto o modernismo, de um modo geral, foram escandalosos em Portugal, como se sabe, e a referida exposição do artista ficaria desconhecida do grande público. Mesmo assim, o conjunto de ações atribuído à chamada Geração de Orpheu seria desconcertante. Como bem afirmou Nuno Júdice, "a irritação provocada por estes 'novíssimos' não é meramente superficial, e resulta de terem sido atingidos os alvos profundos do establishment da época" (JÚDICE, 1982, "Introdução").

Final do século XX. A questão que parece se abrir, no alvorecer do século XXI, em Macau, é: "Seria ainda possível aos artistas e escritores efetuarem a legibilidade de um espaço, agora, situado nas complexidades dos processos de globalização e de uma radical transformação de suas infraestruturas?" O que permitiu que Macau se constituísse como uma região especial foi justamente a sua especificidade cultural e, apesar disso, tanto a manutenção dessa especificidade, construída ao longo da história, quanto o intercâmbio entre as diversas culturas parece ser um desafio gigante, que se desenvolve na inversa proporção dos investimentos que vêm sendo realizados no período pós-transição.

Sendo assim, talvez seja hora de manifestar-nos e, ao modo de Almada Negreiros, dizer que o evento mais importante do ano de 1999 foi a publicação do livro Infraestruturas, de Alberto Estima de Oliveira, pelo Instituto Cultual de Macau, uma re-edição bilingue português-chinês, com tradução feita por Yao Jingming. Uma nova provocação!

Tal como a exposição de Amadeo de Souza Cardoso, a importância do evento não pode aparecer nas estatísticas ou no número do público alvo, mas sim na importância definitiva de um diálogo que só a poesia pode realizar, com o sentido da descoberta que é infinito. E se, para Almada Negreiros, Amadeo de Souza-Cardoso pertence ao que ele chamava de "Pensamento Universal", tenho como suspeita que Alberto Estima de Oliveira pertença a uma "Infralíngua", que só pode ser vestígio da experiência vivida, o caminho do afeto nos confins da própria identidade. Por isso, reafirmo: Infraestruturas, de Alberto de Estima de Oliveira, é mais importante que qualquer outro evento ligado às obras de concreto, executadas em Macau.

\section{Contrastes}

A provocação aqui exposta não busca, de jeito nenhum, diminuir a importância dos programas executados no período de transição, ao contrário. Entre a construção de pontes, portos e aeroporto; rede de saneamento básico e de recolha de lixo, houve um imenso investimento tanto nas áreas do ensino 
quanto da cultura no sentido de se construir uma base para a manutenção da memória e da identidade cultural de Macau. Além da criação formal da Universidade de Macau e do Instituto Politécnico de Macau, houve um crescimento significativo de reedições e novas publicações de livros de autores portugueses, macaenses e chineses. Por isso, não poderíamos pensar na reedição do referido livro de Estima de Oliveira como uma produção isolada. É ela também parte da transformação avassaladora que configurou o projeto de autonomia e, como tal, da busca de sentidos possíveis de um espaço acrescido do adjetivo "especial".

No contexto literário, diversos olhares percorreram o espaço citadino procurando referir a sua localização cultural já que o mar de empreendimentos fora responsável tanto pelo retorno de macaenses que haviam partido em decorrência da situação do pós-guerra como também pela transferência de portugueses vindos dos mais variados pontos das rotas que o imperialismo havia formado. Ou seja, a literatura, como um sistema integrado aos demais, também passaria por alterações radicais.

Por um lado, houve um crescimento do número de autores publicados em Macau. Por outro, as próprias condições de recepção seriam alteradas, já que, no período de transição, as obras de autores macaenses, como as de Henrique de Senna Fernandes, José dos Santos Ferreira (o Adé), Luiz Gonzaga Gomes e Deolinda da Conceição seriam integradas à legitimidade necessária de se configurar a especificidade da cultura da região. Ainda, as obras de autores portugueses, que no território se instalaram, seriam localizadas em uma entre muitas das culturas formativas do território, já afastadas, portanto, de uma qualquer ideia de cultura dominante/colonial.

Sem intenção de inventariar a produção poética deste período, que foi imensa, e que passa por nomes conhecidos do cânone da literatura portuguesa, como os de José Augusto Seabra e de António Manuel do Couto Viana, apenas menciono que, além da re-edição de Infraestruturas, o Instituto Camões, numa ação conjunta com o Instituto Cultural de Macau e o IPOR, lançou a não menos importante Antologia de Poetas de Macau, organizada por Yao Jingming e Jorge Arrimar. Esta foi a primeira (e única) antologia a reunir poetas portugueses e chineses de Macau, selando uma busca de integração a partir da pluralidade de olhares.

Sem dúvida, Macau necessita de uma continuidade de ação políticocultural nessa direção. A vocação poética deste lugar constitui hoje uma tradição que confirma a sua distinção especial e traz interesse para o mundo todo. 


\section{"Asas" e "Concreto".}

Apesar de a toponímia não estar ausente da obra de Alberto Estima de Oliveira, quase nunca é ela o núcleo geográfico da sua escrita. A sua poesia, como "mecanismo inverossímil/ anfiteatro/ do impossível possível" (1999, p. 113) evidencia a margem dos sentidos, um lugar pra lá dos lugares, atravessado de luz e de silêncios. Evidentemente, a poesia de Estima de Oliveira situa-se nas circunstâncias migratórias da diáspora portuguesa a que já me referi anteriormente. Mas como nos lembra o precioso prefácio da reedição de Infraestruturas, escrito por Maria Alexandre, a sua palavra está para além do que diz, além "de uma exterioridade assimilada simbolicamente e com os mitos e arquétipos que as suas vivências de europeu por raiz, angolano por opção telúrica, e de ser universal por imanência" (1999, p. 8). E se, como afirma a prefaciadora, as suas palavras reenviam-nos "ora à presença de um real imediato, ora à presença de um real recriado" (1999, p. 8), é também na incorporalidade que elas manifestam a pura convicção de realizar-se como um "ato insólito". É na margem incorpórea da palavra que reside a sua liberdade. Em vez de ser subjetividade, a sua poesia afirma-se como hecceidade, individualidade de travessia, de uma vida que não pode ser medida apenas pela materialidade do corpo.

Tenho como hipótese que, a poesia, tal como se realiza na obra de Estima de Oliveira, constantemente unida aos fluxos da criação, não se afirma nem como estrutura linguística, mesmo que desta não possa prescindir, nem como sentimento, cuja gênese poderia se localizar na personalidade autoral, nem ainda como puro fingimento, produto de uma racionalidade dramatizada, mas sim como afeto, provavelmente, com o sentido deuleuziano do termo, que indica um processo de desterrritorialização contínua do já conhecido, em que o desejo se marca pela positividade. Não é por acaso que a dor, nas mais variadas expressões de limite, como "barreira" ou "teto", presentifica-se no corpo poético da sua obra. Não estão as dores ali para provocar o sentimentalismo frente à negatividade. Estão ali para alimentar a positividade do desejo, erguendo-se como aporias para deslocar-nos do mundo material. Porque é de "asas" e de "concreto" que esta poesia nos fala. E, neste primeiro livro publicado em Macau, o encontro dessas poderosas vertentes determinam com precisão o espaço e o tempo da sua poesia. impõe.

Logo no primeiro poema do livro, a figura de um cruzamento se

$$
\begin{aligned}
& \text { perpendicular } \\
& \text { rota cruzada } \\
& \text { situação linear }
\end{aligned}
$$

66 fragmentum, N. 35, parte I. Laboratório Corpus: UFSM, Out./ Dez. 2012 
A figura é ambígua porque tanto pode corresponder a uma rota feita de forma perpendicular quanto a uma rota que, ao ser cruzada, é cortada por uma linha perpendicular. O cruzamento, assim, pode referir o próprio percurso do deslocamento ou uma precisa localização em meio ao percurso. Ainda, uma rota é um caminho que vai de um ponto a outro, mas aqui não há qualquer referencialidade. Estamos diante de um poema que, visualmente, corresponde a uma pura linha ou a um ponto formado por duas linhas. Apesar de não haver as referências "de onde até onde", elas estão ali de forma potencial, ou seja, estão ali esvaziadas, mas este vazio é pleno de possibilidades. Elas referem quaisquer pontos geográficos e, por isso, são potencialmente todas as coordenadas espaciais. Ao se deter no movimento que o poema contém, o leitor pode seguir as linhas com o olhar, deixando que surja a figura "+", como imagem da "situação linear". É curioso que, metida no campo das referências culturais, se um intérprete situá-la na cultura cristã, verá logo a "cruz", símbolo da totalidade no amor único de Cristo e, se pensar na cultura chinesa verá o número "dez"- shí ou yat - que é também um retorno simbólico ao uno no sentido de totalidade, tanto que, em muitos textos clássicos chineses, aparece a expressão "dez mil coisas", querendo dizer "todas as coisas". De fato, nestes primeiros versos, as linhas permanecem como cifras de um sinal a ser descoberto pelo olhar. Pode também significar a relação universal entre tempo e espaço que engendra o destino humano. E, neste caso, a ambiguidade cultural parece reforçar a abstração que as palavras reivindicam, correspondendo à busca de uma totalidade para a qual elas apontam, uma noção de "uno" que põe o invisível de forma bem visível.

Em sentido estético, o invisível, o indizível, o imaterial ou o incorporal, formas diferentes de se expressar o vazio, parecem ter sido exigência e busca dos artistas do século XX, apesar de, provavelmente, terem sido evocados pela arte, desde sempre. No século XX, no entanto, com a progressiva expansão das doutrinas do oriente no ocidente, como o zen budismo e o taoísmo, o resgate de formas poéticas como as antigas quadras chinesas ou os hai kai japoneses, as noções de vazio e de silêncio parecem ter sido exaltadas como nunca antes. Por outro lado, desde o final do século XIX, as vanguardas européias procuraram revelar uma luz simbólica consistente junto à representação de formas concretas. Desde Cézanne e aqueles por ele influenciados, como Mondrian, Malévitch e Duchamp, que a arte procurou materializar a luz, o invisível que provê o relevo e a profundidade para o visível, no sentido de se fazer uma "não arte", uma arte que rasurasse a figuração. Através da liberdade de composição, de cores e de ângulos retos, esses artistas procuraram separar a forma do conteúdo concreto para identificá-lo ao conteúdo abstrato e elementar.

A possibilidade de fusão do invisível à matéria de forma objetiva em vez de constituir correspondências por dissipação, como no simbolismo, de 
forma mais geral, traria novas possibilidades. $\mathrm{Na}$ literatura não seria diferente. Ainda, naquela de expressão portuguesa e, segundo artigo comparativo entre as poesias de Pessanha e Pessoa, Horácio Costa (2006), perseguindo a tendência axiomática da poética moderna que assume certas convergências entre a escritura oriental e ocidental, tal qual em Pound, interpreta alguns poemas de Pessanha, como "Violoncelo", de forma a aproximá-los dos aspectos fundamentalmente imagéticos, numa estrutura prismática em que o indizível passa a ocupar cada vez mais o espaço da linguagem.

Para Anne Cauquelin, se uma das marcas da arte contemporânea é o vazio que é feito de fluidez, isso não acontece simplesmente por conta das influências orientais, mas teria sido o resultado de um longo processo em que, desde a teoria dos incorporais dos estóicos, o antigo estaria se reabilitando no novo. Segundo a filósofa, os estóicos pensam o universo como uma totalidade animada por um sopro que o atravessa em expansão e contração infinitamente. Assim, se o universo é infinito é porque mundo e vazio coabitam em respiração. Para o estóicos, todas as causas são corporais inclusive os espíritos como potencialidades, pensado fora de qualquer proposição mística. Se o universo é infinito, o mundo se faz e se desfaz dentro dele, sendo contrariamente finito. Nas linhas que Estima de Oliveira nos deixou, temos uma cosmologia muito próxima dessa formulação:

\author{
em cada horizonte \\ um sinal \\ em cada homem \\ uma dimensão \\ são linhas \\ diferentes \\ uma horizontal \\ ilimitada \\ outra \\ conforme a condição (1999, p. 33)
}

$\mathrm{Na}$ tensão das diferentes condições, nem sempre favoráveis, e a sua transcendência, os poemas nos põem numa espécie de olho do furacão. Existe um "solo sagrado da amargura" (1999, p. 49). Existe "a terra/ onde/germina/minha própria/fraqueza" (p. 89). Existem "arrozais regados a sangue/ no estio da loucura" (p. 49) E Existe no "corpo/angústia" (p. 131). Se a canoa vara na lama, a gaivota cai na noite, os lagos secam e "a palavra/ 
desfaz-se/ num murmúrio de humidade" (p. 117), o jeito é tentar tocar "no vértice/ do nexo" (p. 69).

"É urgente ter asas" (p. 63), dita a poesia.

amar

descobrir

a proposta

do infinito (1999, p. 65)

Neste admirável convite de se buscar o intangível, de se disponibilizar para a alteridade radical num gesto de afeto, está a necessidade de se fazer "um mergulho/ consciente/ na essência da vida" (p. 105). Em cada vôo, iluminamse relações sociais e define-se o espaço de intimidade de um "eu" que lança um desafio a cada obstáculo encontrado.

Afinal, toda travessia é feita de risco. Todo movimento exige parada. No infinito, é o limite que o evidencia. A preferência pelo vôo, manifesta, nesta poesia, como compreensão de uma relação transcendente entre $\mathrm{O}$ exprimível e o lugar, determina-se por vários limites.

\author{
estou em casa \\ olho as estrelas \\ encontro o tecto
}

barreira do concreto (1999, p.37)

O "tecto", limite da casa, define o microcosmo em relação ao macrocosmo, espaço das estrelas, incomensurável. $\mathrm{O}$ olho incide de encontro ao teto que, além de ser limite, é oposição, aporia num jogo paradoxal da linguagem, pois, no nível simbólico, as estrelas são também o mundo interior, a vontade do "eu", esperança, enquanto o teto é metonimicamente a opacidade da realidade exterior. Existe um deslocamento no olhar que se projeta em direção às estrelas, encontrando o teto. Tudo se modifica. Temos, assim, uma inversão dos espaços interior e exterior, que participam da ipseidade de se estar "em casa". O importante é a relação entre os signos e não a identidade de cada um, porque é o movimento que caracteriza ao mesmo tempo a transcendência e a dificuldade de isso acontecer, o impedimento e a resistência, a resistência do olhar contra a resistência do teto. A aporia marca um modo de estar no mundo, uma forma um tanto incomodada de ser, uma ética, através do olho que enfrenta o teto para desacomodar o mundo habituado.

Interpretando, a dura realidade é a finitude do ser enquanto as estrelas são metonimicamente sinais da respiração universal infinita. Ambas 
estão na mira do olho, coexistindo na paradoxal consciência de infinitude do afeto na finitude do corpo.

O processo se recria em outros poemas. Assim também, há uma "barreira/ entre a cidade/ e horta" (1999, p. 39), significando a fronteira entre mundos diferentes, ou ainda um duplo obstáculo na "barreira de frio/ montanhas separadas/ pelo rio"(1999, p. 41), em que o rio é fronteira entre semelhantes e o frio é impedimento à travessia, é paralisia, a evidente impossibilidade de fluir. No entanto, no movimento do corpo poético que Estima de Oliveira inventa, é também vacuidade, a mesma que surge na madrugada, ou, ainda, como no último poema do livro, no rumor profético dos búzios. O destino permanece no "rio dos olhos" (p. 75) que tudo pode verter, envolver com a cumplicidade de um diálogo feito de abertura ao imaginável e inimaginável. Porque só o "desintegrado/ deixa/ de esperar" (p. 59). Enquanto houver corpo, "pedras, [...], e o amor/ e o tecto, [...] " (p. 47), a poesia de Estima de Oliveira continuará a nos arremessar ao expectante infinito.

Neste nosso "momento concreto", quase dez anos depois da transferência de Macau, não se pode recusar a importância da obra deste poeta para a compreensão deste lugar, especialmente, em sua contemporaneidade.

\section{Referências}

ALEXANDRE, Maria. Notas de uma leitura possível. In: ESTIMA DE OLIVEIRA, Alberto. Infraestruturas. Macau: Institituto Cultural de Macau, 1987.

ALMADA NEGREIROS, José. Manifestos e outros textos de intervenção. Lisboa: Imprensa Nacional Casa da Moeda, 1992.

ALMEIDA, Maria do Rosário. Chu Kong. Macau: Instituto Cultural de Macau, 1987.

CAUQUELIN, Anne. Frequentar os incorporais. Contribuiçào a uma teoria da arte contemporânea. Traduzido por Marcus Marcionilo. Fréquenter les incorporels (2006). São Paulo: Martins Fontes, 2008.

COSTA, Horácio. Poemas prismáticos: Pessoa e Pessanha. In: LOPONDO, Lílian (org.). Dialogia na literatura portuguesa. São Paulo: Scortecci, 2006. DIAS, Fernanda. Horas de papel: poemas para Macau. Macau: IPOR, 1992. ESTIMA DE OLIVEIRA, Alberto. Infraestruturas. Coleção Poetas de Macau. Macau: Instituto Cultural de Macau, 1999.

70 fragmentum, N. 35, parte I. Laboratório Corpus: UFSM, Out./ Dez. 2012 